\title{
Production and Optimization of Pseudomonas fluorescens Biomass and Metabolites for Biocontrol of Strawberry Grey Mould
}

\author{
Wafaa M. Haggag ${ }^{1}$, Mostafa Abo El Soud ${ }^{2}$ \\ ${ }^{1}$ Department of Plant Pathology, National Research Centre, Dokki, Egypt; ${ }^{2}$ Biotechnology and Genetic Engineering Unit, National \\ Research Center, Dokki, Egypt. \\ Email: wafaa_haggag@yahoo.com
}

Received April 18 ${ }^{\text {th }}, 2012$; revised May 16 ${ }^{\text {th }}, 2012$; accepted May 24 ${ }^{\text {th }}, 2012$

\begin{abstract}
Pseudomonas species have been widely studied as biological agents (BCAs) and it is alternative to the application of chemical fungicides. Our objective was to optimize nutritional and environmental conditions of the isolated Pseudomonas fluorescens fp-5 for biomass and metabolites production and to evaluate its against the grey mould disease caused by Botrytis cinereaon strawberry plants under field conditions. Pseudomonas fluorescens, showed antagonistic properties, in vitro, against the pathogen Botrytiscinerea. Effect of the separated secondary metabolites on the fungal growth by broth dilution technique and antifungal activity by agar well diffusion technique was studied. Response surface methodology was used to investigate the effects of four fermentation parameters $(\mathrm{pH}$, incubation time, carbon and nitrogen concentrations) on biomass and bioactive metabolites [antibiotic phenazin and siderophore] production. Glycerol was found to be the best carbon source for improved biomass and metabolites production. Meanwhile, peptone and yeast extract were found to be the best nitrogen source. Analysis of each formulation revealed that glycerol oil at $0.01 \%$ the best oil used for protect $P$. fluorescens for 3 months Under natural condition, $P$. fluorescens formulation was effective in reducing $B$. cinerea disease in strawberry leaves and fruits. Pre-harvest treatment protected fruits from Botrytis post-harvest disease in comparing of fungicide. In addition, the obtained results showed that bacterial treatment significantly increased the growth parameters as well as dry weights and yield.
\end{abstract}

Keywords: Botrytis Bunch Rot; Pseudomonas fluorescens; Strawberry Blight

\section{Introduction}

Botrytis fruit rot (gray mold) is caused by the fungus Botrytis cinerea and is the most important disease of strawberry worldwide and in Egypt [1]. The disease can cause important fruit losses on strawberry plants before or after harvest worldwide and it is estimated that they can cause yield losses up to $50 \%$ for untreated strawberries [2-4]. When we consider the pathogenicity of $B$. cinerea, it produces phytotoxic metabolites to kill its host and an array of enzymes, including cell wall-degrading enzymes, for the decomposition and consumption of plant biomass [5]. Control of Botrytis fruit rot requires a combination of chemical, cultural and biological control methods. Main recommendations for reduction of the infection with Botrytis are the usage of highly active botryticides. The removal and destruction of dead or infected plant parts as well the removal of diseased fruit from within the plant canopy will reduce the amount of inoculum capable of producing new infections. The introduction of biotechnology products into agriculture have been improved in order to increase yields and crop quality, extremely important for developing countries [6]. The genus Pseudomonas, especially the group of fluorescent Pseudomonas, produces secondary metabolites with antagonistic and/or antibiotic activity against various pathogens. Siderophore produced by Pseudomonas spp. have been employed efficiently as biocontrol agents against certain soil-and foliar borne plant pathogens. Siderophores, whose chemical structures depend upon their producer microorganism, may provide iron (III) to some vegetable cells. These metabolites, due to their antagonistic capability against pathogenic microorganisms, could act as growth factors in plants [7]. Also, siderophore use in medicine for iron and aluminum overload therapy. Other desirable features for a potent organism are that it should have the ability to synthesize anti-fungal metabolites, such as the antibiotic phenazin 
which suppress the growth of fungal pathogens [7]. This study investigated to study 1) the detection of a possible inhibitory action of fluorescent Pseudomonas against Botrytis cinerea 2) characterization of an antifungal metabolite produced by fluorescent Pseudomonas 3) develop a process which produces improved biomass, siderophore and phenazin in submerged fermentation. The culture broth so obtained used for bio-inoculant preparations for controlling of strawberry grey moulds.

\section{Materials and Methods}

\subsection{Microorganisms}

Fluorescent pseudomonad strain Pf-5 used in the present investigation was isolated from strawberry plants and identified in Plant Pathology Department, National Research Centre, Egypt. Fluorescent pseudomonad culture was maintained in King's B medium.

B. cinerea isolated from diseased fruit was cultivated on Potato Dextrose Agar (PDA, Difco) medium.

\subsection{Detection of Antagonistic Activity in Vitro Assay}

Potato Dexstrose agar plates were inoculated by a streak of the antagonistic bacterial strains. A disc $(9 \mathrm{~mm}$ in diameter) of the fungi was punched out with a sterilized corkborer from advancing zones of the fresh culture, and placed on either side of bacteria inoculated plates. The petri plates were incubated at $25^{\circ} \mathrm{C} \pm 2^{\circ} \mathrm{C}$ for 5 days. The diameters of hyaline inhibition zones were measured and experiment was repeated five times. Antifungal activity of free culture broth free culture broth was assay using wells of $6 \mathrm{~mm}$ were punched for agar well diffusion assay method. Different concentration $(25 \mu \mathrm{l}, 50 \mu \mathrm{l}$, and 75 $\mu \mathrm{l})$ of overnight free culture broth of potential antifungal $P$. fluorescens was centrifuged at $10,000 \mathrm{rpm}$ for $20 \mathrm{~min}$ and poured in to the well agar plates. Then the plates were incubated at $25^{\circ} \mathrm{C}$ for $24 \mathrm{hrs}$, where upon inhibitory activity was observed as a zone of clearing around the wells. The diameter of the clearing zones was measured in $\mathrm{mm}$.

\subsection{Improving Production of Bacteria}

Improving production of Pseudomonas fluorescens was carried out in the unit of pilot plant biotechnology and genetic engineering (pilot, semi-industrial, Centre Lab.), the National Research Centre. The main objective of this research task is to improve rearing procedures of the BCAs production using locally available materials, and easier procedures for inoculation, extraction and purification of yielded inocula. In addition, efforts was made to optimize the quantity of medium per flask (inoculum size), conditions affecting the growth of $P$. fluorescens, the culture time, suitability of strains for the modified culturing conditions and improving the shelf life of produced bio-fungicides.

\subsubsection{Bacteria Cultivation and Optimization}

\subsubsection{Incubation Period}

The optimization of composition of incubation period, and cultural conditions was carried out based on stepwise modification of the governing parameters for antifungal production. The cultures were transferred to seed broth ( $200 \mathrm{~mL}$ of Medium) contained in a $500 \mathrm{~mL}$ Erlenmeyer flask and incubated at $30^{\circ} \mathrm{C}$ on a rotary shaker $(175 \mathrm{rpm})$ for 6 - 8 hours. A $500 \mathrm{~mL}$ Erlenmeyer flask containing $100 \mathrm{~mL}$ of the same seed medium was incubated as specified above.

Estimation of Dry Cell Weight and Siderophore: The cell growth was estimated turbidimetrically using Helios Thermo Spectronic spectrophotometer (OD). The quantification of hydroxamate-type siderophore was done according to [8]. The siderophore concentration ( $\mathrm{g} / \mathrm{l})$ was calculated using the expression O.D $400 \mathrm{~nm} \times \mathrm{MW} / \varepsilon$. The values of extinction coefficient, $\varepsilon=16,500 \mathrm{M}^{-1} \cdot \mathrm{cm}^{-1}$ and of molecular weight, $\mathrm{MW}=1500 \mathrm{Da}$ were used.

Estimation of Phenazin: The pseudomonad strain Pf-5 was cultivated in shake flask. The harvested broth was centrifuged and the supernatant was pooled. The $\mathrm{pH}$ of the supernatant was adjusted to 2.0 by adding $4 \mathrm{~N} \mathrm{HCl}$ and extracted twice with equal volume of ethyl acetate. The extracts, which contained Phenazin were evaporated to dryness in vacuo. The extracted crude antibiotic was dissolved in methanol and stored in $-20^{\circ} \mathrm{C}$ for further purification and analysis. Purification was performed by column chromatography on a silica gel C-200 $(22 \mathrm{~mm} \times$ $200 \mathrm{~mm}$ ). The crude extract dissolved in methanol was re-dissolved in $20 \mathrm{~mL}$ of ethyl acetate and applied to the column. After washing with $50 \mathrm{~mL}$ of ethyl acetate, the column was eluted with $300 \mathrm{~mL}$ of toluene-acetone (4:1 $\mathrm{v} / \mathrm{v})$. Five milliliter fractions were collected and examined for the presence of the antibiotic by thin-layer chromatography in UV detection chamber against the standard antibiotic. Camag HPLC instrument (Anchrom, Mumbai) was used for quantitative analysis of the antibiotic using a standard antibiotic (Sigma chemical).

Studying the time course of different metabolites production by isolate in medium under shaking condition: Erlenmeyer flasks containing the previously mentioned medium were prepared, inoculated and incubated as described above. Over an incubation period of 7 days, one flask was removed every $8 \mathrm{~h}$, determination of biomass (optical density and dry weight), residual substrate, inhibition zone and metabolites products. 


\subsubsection{Effect of Different Carbon Sources}

The effect of replacing glucose in the cultivated medium with other tested carbon sources on antibiotic production was investigated in Bacillus isolate. The tested carbon source was added at a concentration equivalent in carbon content to that of glucose $(10 \mathrm{~g} / \mathrm{L})$. The tested carbon sources were (D-glucose, D-fructose, sucrose, maltose, lactose, galactose, D (+)-mannose, raffinose, glycerol, Starch, Cellulose, treated molasses and none treated). Erlenmeyer flasks $(250 \mathrm{ml})$ containing $50 \mathrm{ml}$ of the medium devoid of its own carbon source and containing the equivalent amount of other carbon sources were prepared, inoculated and incubated as described above. At the end of the incubation period, samples were removed for determination of biomass (optical density and dry weight), residual substrate and inhibition zone.

Effect of variable concentrations of the selected carbon source: Flasks $(250 \mathrm{ml})$ with $50 \mathrm{ml}$ aliquots of the medium containing different concentrations of the carbon source that showed promising results were prepared. These carbon source was D-glucose $(1 \%, 1.5 \%$, $2 \%, 2.5 \%, 3 \%, 3.5 \%, 4 \%, 5 \% \mathrm{w} / \mathrm{v})$. The flasks were terminally sterilized, inoculated and incubated as described above. At the end of the incubation period, samples were removed for determination of biomass (optical density and dry weight), residual substrate and inhibition zone.

\subsubsection{Effect of Different Nitrogen Sources}

This was studied by replacing sodium nitrate of medium with other tested nitrogen sources. The tested nitrogen source was added at a concentration equivalent in nitrogen content to that of sodium nitrate $(2.5 \mathrm{~g} / \mathrm{L})$. The studied nitrogen sources were classified into organic (urea, yeast extract, peptone, tryptone and corn steep liquor) and inorganic sources (sodium nitrate, potassium nitrate, ammonium nitrate, ammonium chloride, ammonium sulfate, Di Ammonium hydrogen phosphate). Erlenmeyer flasks $(250 \mathrm{ml})$ containing $50 \mathrm{ml}$ aliquots of MSM devoid of its own nitrogen source and containing the equivalent amount of other nitrogen sources were prepared, inoculated and incubated as described above . In case of urea, a stock solution was prepared; filter sterilized $(0.22 \mu \mathrm{m})$ and then an aliquot containing the required amount of urea was incorporated aseptically. The nitrogen content in CSL, as known from literature, was $3.3 \% \mathrm{w} / \mathrm{w}$, so nitrogen molar ratio for CSL was 0.033 . However, for yeast extract, peptone, tryptone; the nitrogen ratio was $0.098,0.14$ and 0.127 respectively, as claimed by the manufacturers. At the end of the incubation period, samples were removed for determination of biomass (optical density and dry weight), residual substrate and inhibition zone.

\subsection{Formulation}

The formulation of Pseudomonas fluorescens was prepared using $0.01 \%$ as glycerol oil, soybean oil, polysaccharide as methylcellulose (CMC), D-glucose at $0.1 \%$ concentration. The liquid formulations were evaluated initially during storage periods at $4{ }^{\circ} \mathrm{C}$ temperature. The percent of survival bacteria were measured during three months.

\subsection{Testing of Pseudomonas fluorescens on Controlling of Strawberry Blights under Field Conditions}

Field experiments were conducted at El-Qalubeia governorate, Egypt to study the effect of formulation of Pseudomonas fluorescens against Botrytis cinerea of strawberry plants cv. Sweet charl pre and after-harvest in 2010 and 2011. Field experiments were conducted under natural infection in plots $(4 \times 8 \mathrm{~m})$ each comprised of 8 rows (32 holes/row) in a randomized complete block design with three replicates. Formulation of $P$. fluorescens was applied as foliar application on strawberry plants after 30, 50 and 70 days of planting Water and fungicide (Redomil-plus at $2 \mathrm{~g} / \mathrm{l}$ ) were applied as control .

Disease assessment: Disease was recorded up to 100 days of planting. The percentages of infection and severity of Botrytis (1 - 9 Scale, where $1=$ free from disease, and $9=$ killed) were measured continuously during growth period.

Determination of yield: Accumulated strawberry yield (Ton/eddan) compared with fungicide was determined.

Statistical analysis: The collected data were evaluated statistically using the software spss for Windows (release 7.5.1, 20 December 1996; SPSS Inc., Chicago, IL). Data were subjected to analyses of variance and treatment mean values were compared by a modified Duncan's multiple test $(\mathrm{P} \leq 0.05)$.

\section{Results}

\subsection{Bioassay}

Pseudomonas fluorescens Pf-5 was isolated from phylloshere of strawberry plants and identified based on morphological, cultural and biochemical characteristics. Measurement of inhibition zones (expressed in $\mathrm{mm}$ ) as observed in agar plate and well diffusion assay methods (Table 1). The culture filtrate showed antifungal activity of $P$. fluorescens against Botrytis at all concentrations.

\subsection{Bacteria Cultivation and Optimization}

From the Figure 1, we notice that the optical density 
Table 1. Antifungal activity of Pseudomonas fluorescens against Botrytis.

\begin{tabular}{|c|c|c|c|c|}
\hline \multirow{2}{*}{ Treatments } & \multirow{2}{*}{$\begin{array}{c}\text { Antagonistic } \\
\text { (zone inhibition } \\
\text { mm) }\end{array}$} & \multicolumn{3}{|c|}{$\begin{array}{c}\text { Cell free culture } \\
\text { (zone inhibition mm) }\end{array}$} \\
\hline & & $20 \mu 1$ & $50 \mu \mathrm{l}$ & $75 \mu 1$ \\
\hline P. fluorescens & $45.8^{*}$ & 20.7 & 40.8 & 61.6 \\
\hline
\end{tabular}

*Mean of the three replicates in the inhibition assay.
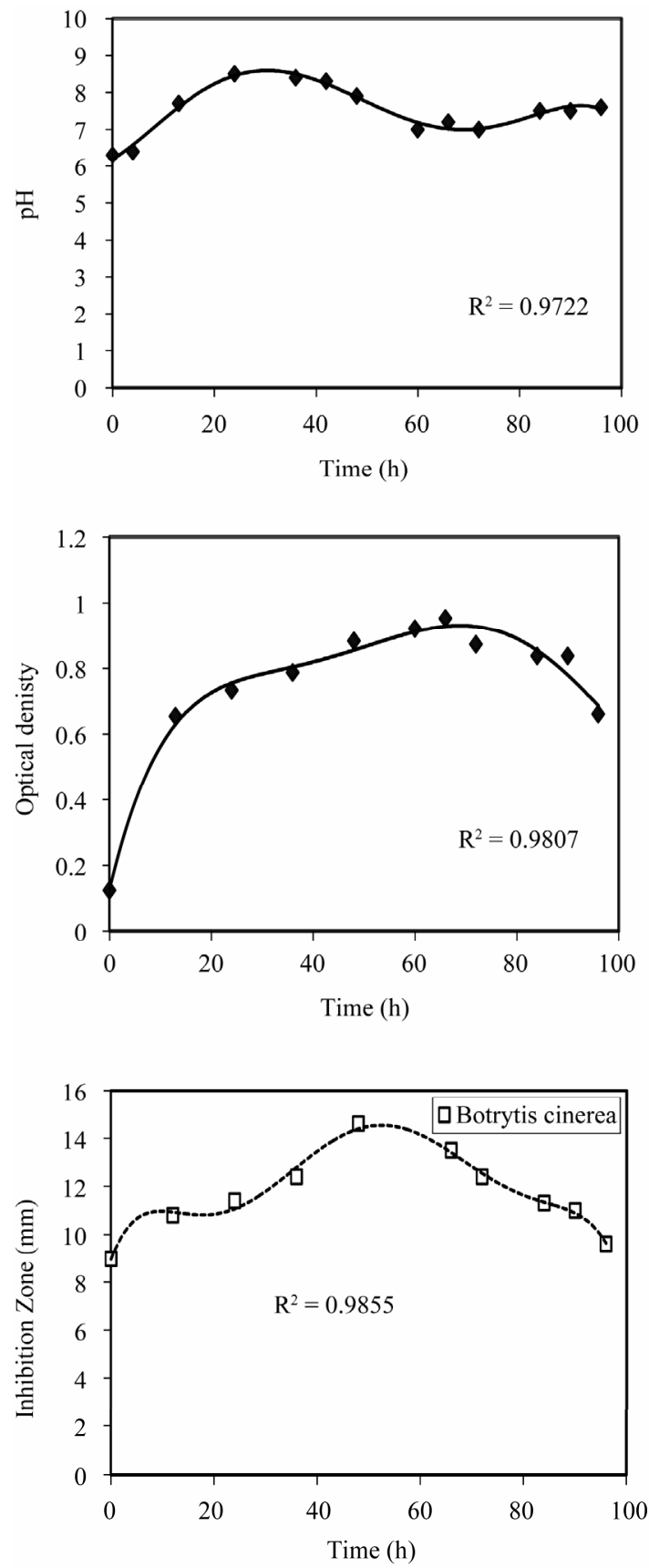

increases sharply with time till $24 \mathrm{hrs}$ then its rate is almost zero for the next $42 \mathrm{hrs}$ and after that decreases with time. This is confirmed in the $\mathrm{pH}$ profile, where the $\mathrm{pH}$ increases to 8.5 at $24 \mathrm{hrs}$ incubation time and stabilizes for the next $24 \mathrm{hrs}$ then starts decreasing to 7 at 60 hrs and remains constant for $12 \mathrm{hrs}$ then increases again. The time course for dry weight also in agreement with the previous observations, whereas the maximum dry weight is reached at $24 \mathrm{hrs}$ and stabilizes till $48 \mathrm{hrs}$, then
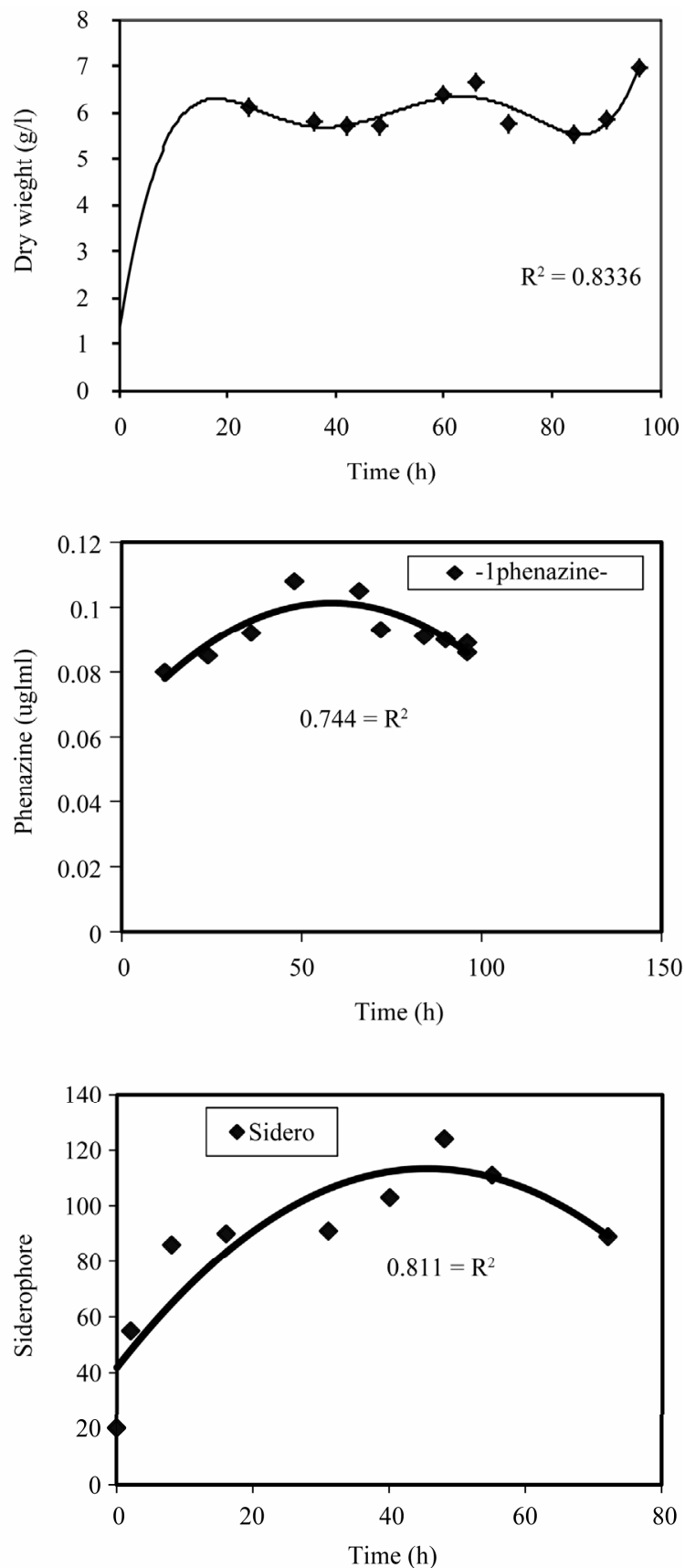

Figure 1. Effect of incubation time on the growth, inhibition activity and production of antifungal of Pseudomonas fluorescens. 
after that the value of dry weight increases with time. In the inhibition zone curve, $B$. cinerea follow the same pattern whereas the inhibition zone increases with incubation period till $48 \mathrm{hrs}$ then starts to decrease. Production of siderophore and antibiotic phenazine increased radically from the beginning of incubation time till $72 \mathrm{hrs}$ then decreased. From the experimental results it was noticed that by using different types of carbon source for the growth of $P$. fluoresens, the dry weight concentration was almost maximum with glycerol as a carbon source. Also, the production of phenazine-1-carboxylate and Siderophore were maximum with glycerol. The zone inhibition of $B$. cinerea was maximum by using glycerol (Figure 2). So, the glycerol was chosen as an optimum carbon sources for $P$. fluorescens. By using different concentration of glycerol for the growth of $P$. fluoresens, the dry weight concentration increased gradually with in-
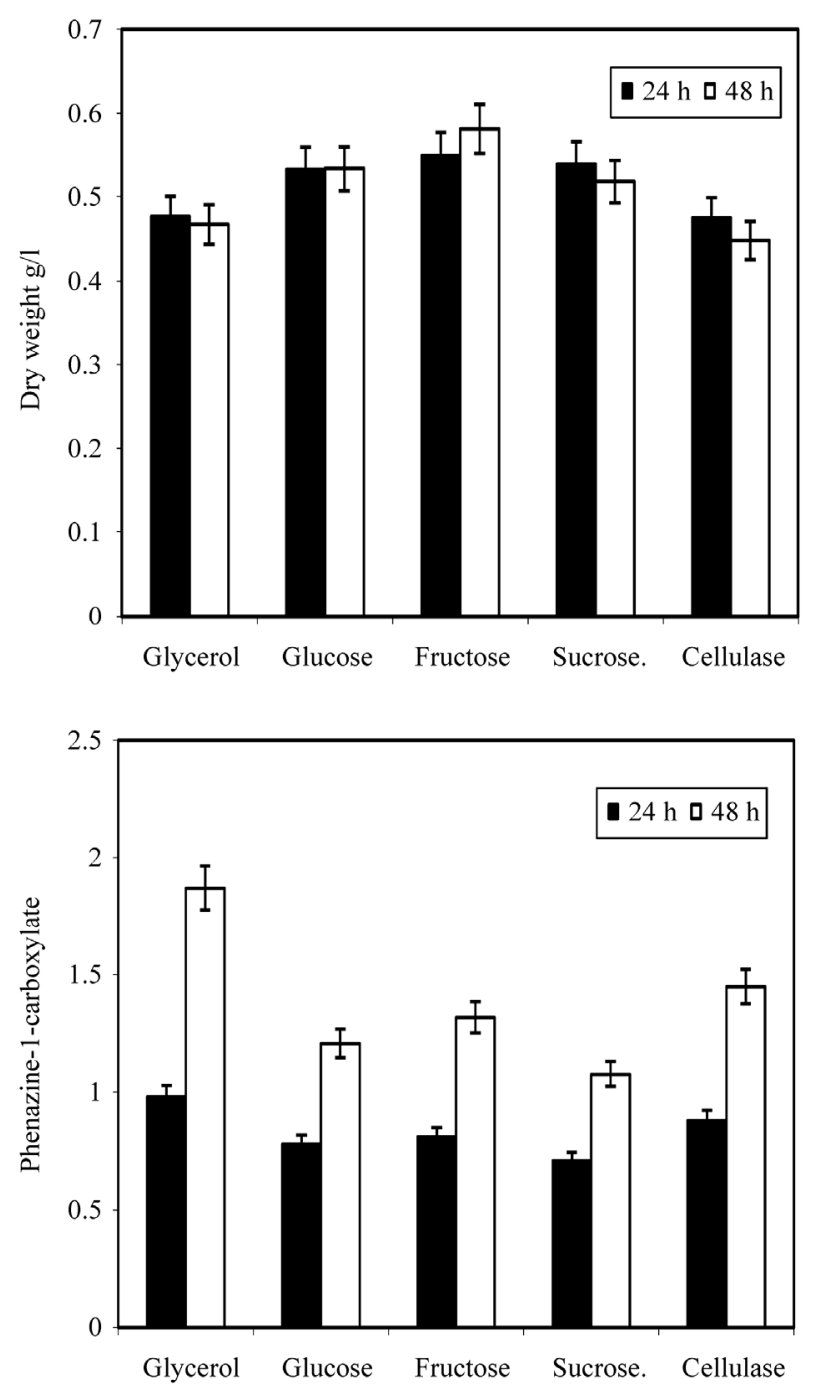

creasing the glycerol. Also, the production of phenazine1-carboxylate and Siderophore increased by increasing the glycerol concentration till $1.5 \% \mathrm{v} / \mathrm{v}$ then decreased again. The zone inhibition of $B$. cinerea, increased by increasing the glycerol concentration till $1.5 \% \mathrm{v} / \mathrm{v}$ then decreased (Figure 3). From the previous observations, $1.5 \% \mathrm{v} / \mathrm{v}$ was chosen as the optimum glycerol concentration.

By using different types of nitrogen source for the growth of $P$. fluorescens it was noticed that the maximum biomass growth was obtained using peptone and yeast extract in equal ration as a nitrogen source. Also the maximum zone inhibition for Botrytis and the maximum production of Siderophore and phenazine-1-carboxylate were obtained with peptone and yeast extract in equal ratio in the media (Figure 4). So, the optimum nitrogen source chosen was an equal ratio of peptone and
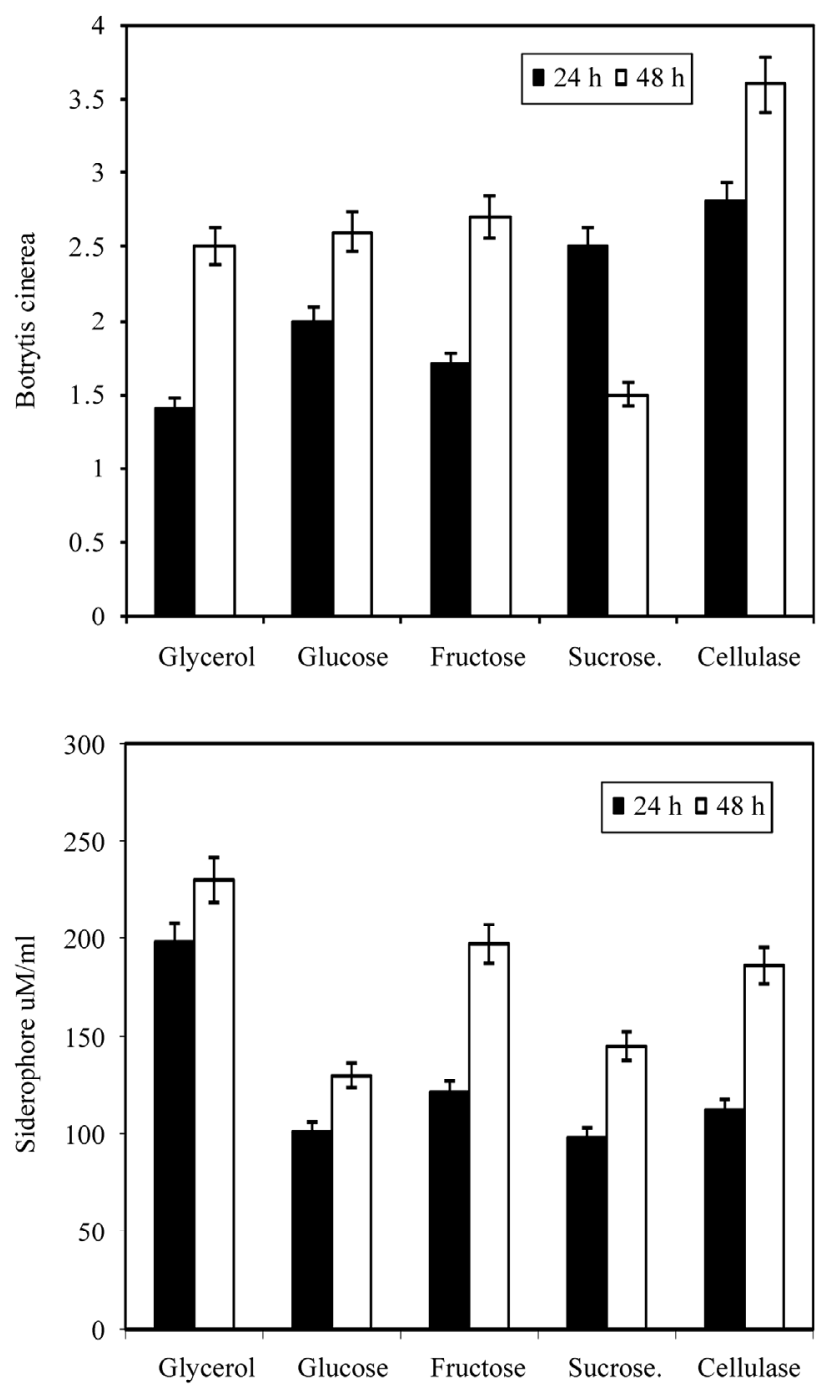

Figure 2. Effect of different carbon sources on the growth, inhibition activity and production of antifungal of Pseudomonas fluorescens. 

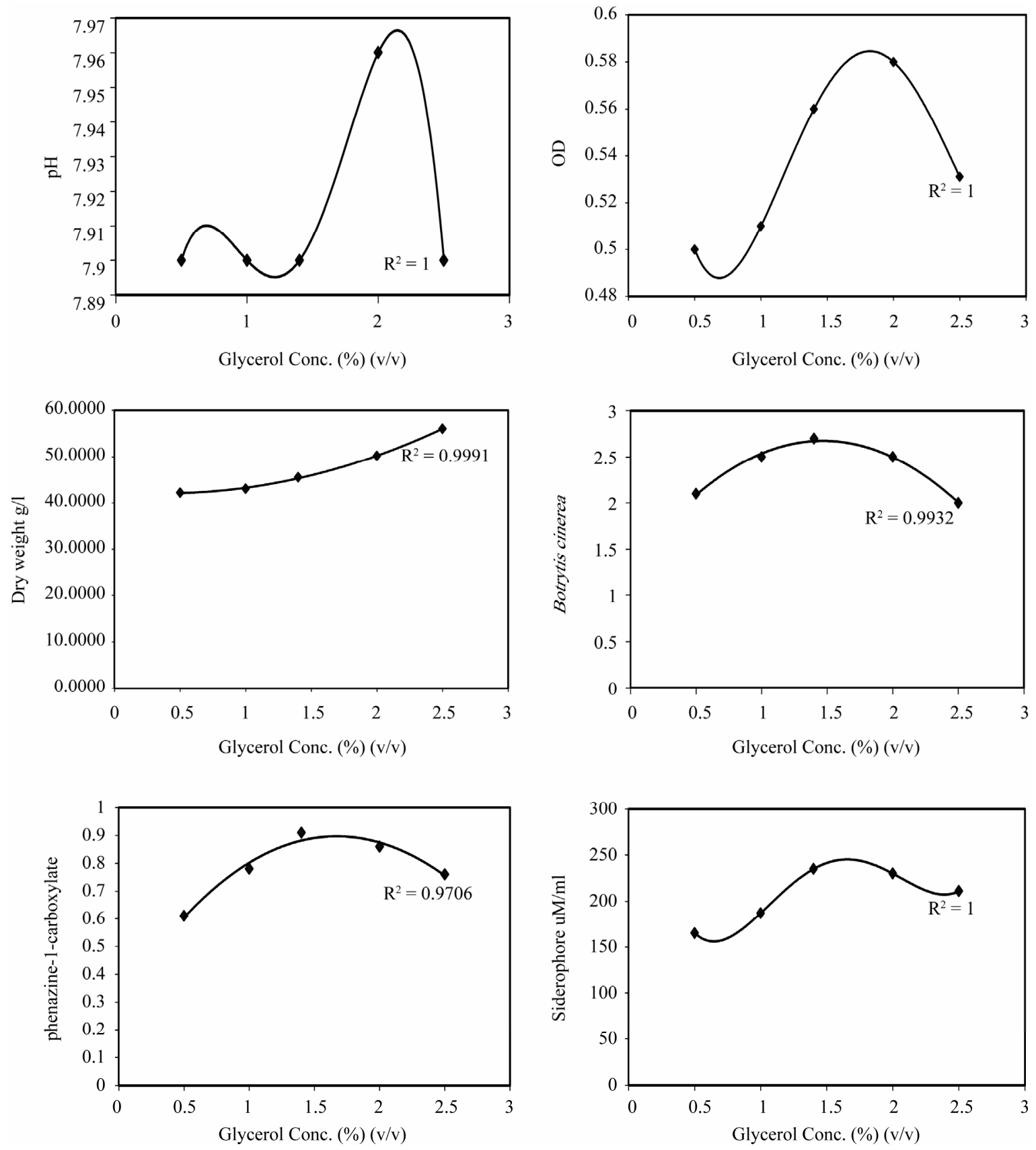

Figure 3. Effect of different carbon concentrations on the growth, inhibition activity and production of antifungal of Pseudomonas fluorescens.

yeast extract.

\subsection{Fermentation and Formulation}

As a part at the fermentation processes development, previous optimum conditions were used for mass production of BCAs. The pilot process development started by searching a low-cost production medium and establishing if the viable cells produced in pilot fermentors with this latter medium were as effective in antagonism as those produced in laboratory medium in Petri plates or in $250 \mathrm{ml}$ shaking flasks. This allowed to continue the development of the liquid fermentation and the scale-up production. In general, all formulations had a longer shelf-life at $4^{\circ} \mathrm{C}$ for three months. Analysis of each formulation revealed that glycerol oil at $0.01 \%$ the best oil used for protect $P$. fluorescens for 3 months in compared with untreated control (Figure 5). So, glycerol oil was used in the fermentation and formulation process of $P$. 

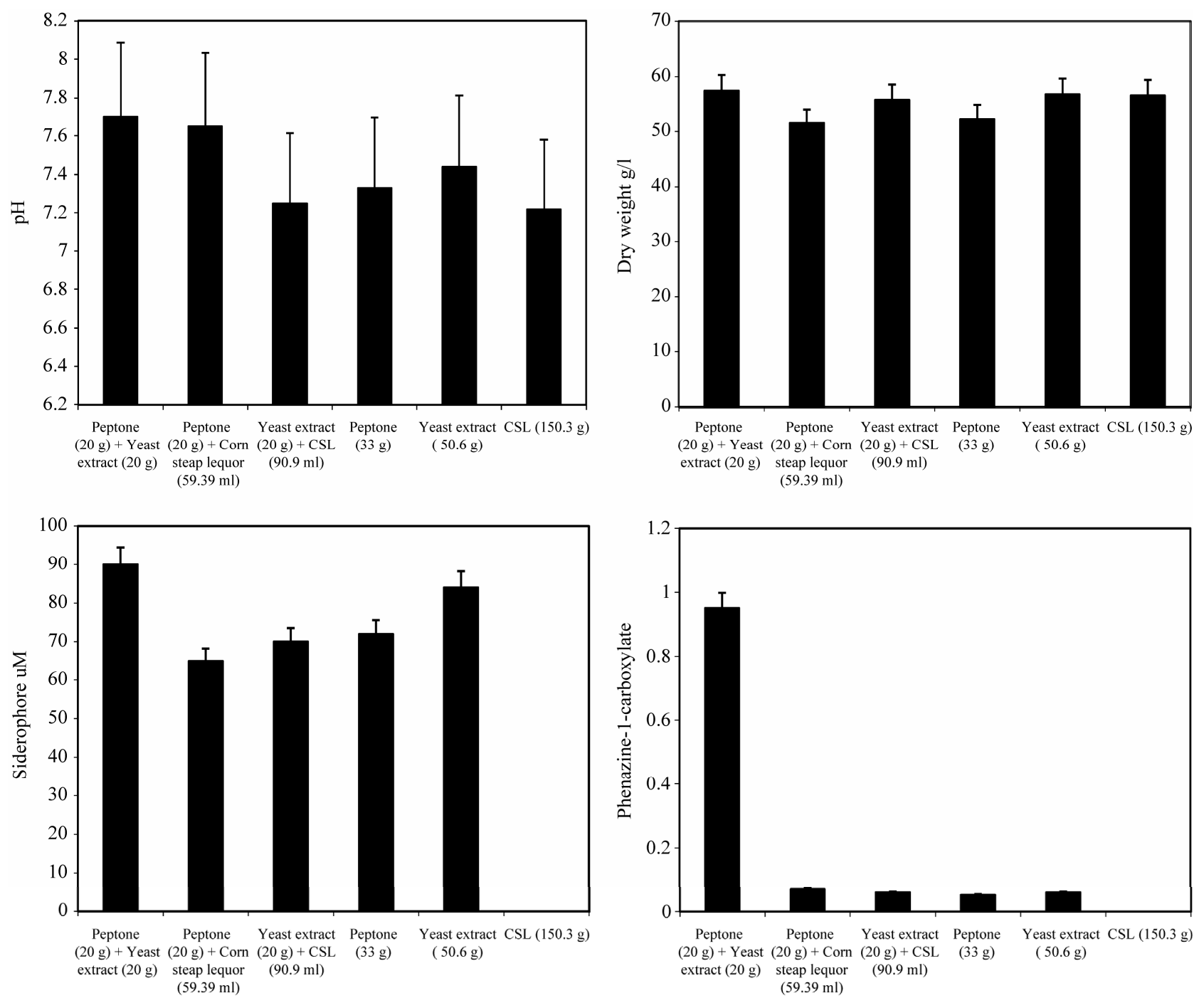

Figure 4. Effect of different nitrogen sources on the growth, inhibition activity and production of antifungal of Pseudomonas fluorescens.

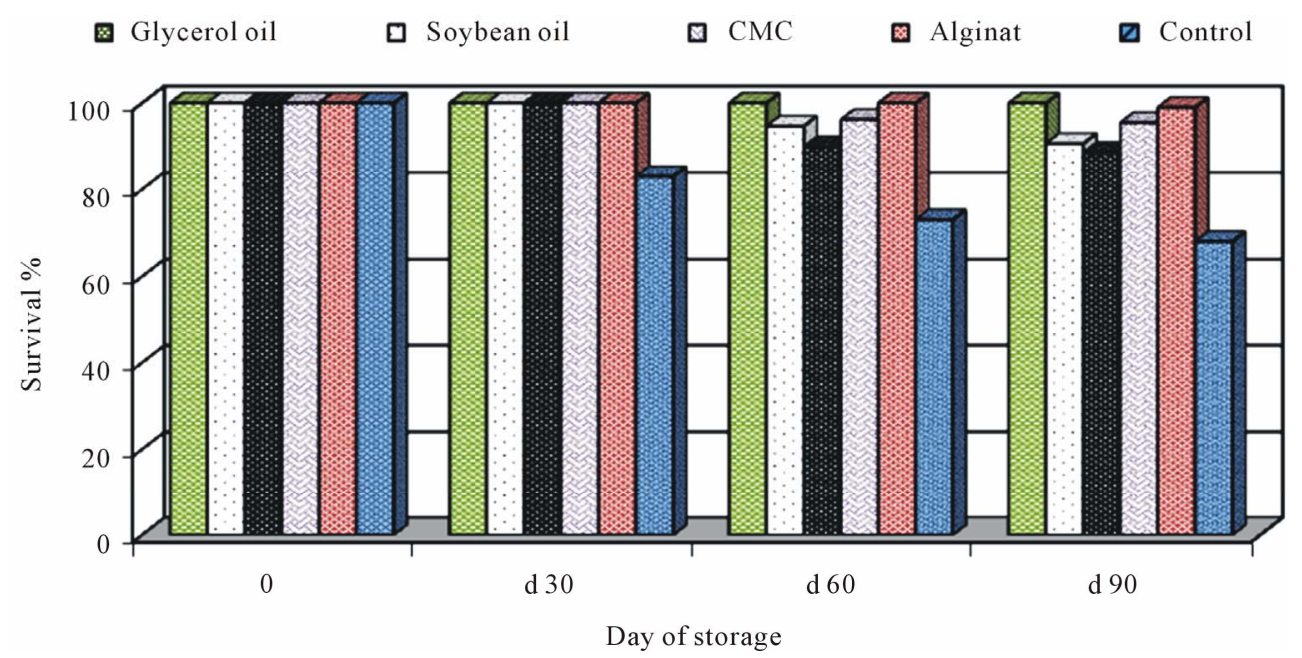

Figure 5. Effect of different formulation on the survival of Pseudomonas fluorescensduring storage periods. 
fluorescens.

\subsection{Effect of Pseudomonas fluorescens on Grey Mould Disease of Strawberry Plants under Field Conditions}

The effect of application of glycerol oil formulation of Pseudomonas fluorescens on grey mould disease incidence on flower and fruits of under natural infested conditions was investigated. Data in Table 2 indicated that flower and fruits were susceptible to infection by $B$. cinerea expressed as disease severity. Data also show that disease severity were decreased by spraying the plants with Pseudomonas fluorescens compared with fungicide.

\subsection{Effect of Pseudomonas fluorescens on Some Vegetative Characters and Yield of Strawberry Plants under Field Conditions}

The effect of glycerol oil formulation of Pseudomonas fluorescenson some vegetative characters of strawberry plants i.e. number of leaves, fresh and dray weight/plant were determined. Results in Table 3 Indicate that Pseudomonas fluorescens had positive effect on fresh and dry weight/plant. Results in Table 3 indicate that Pseudomonas fluorescens significantly increase the strawberry yield. Moderate increase was obtained with treat fungi- cide.

\section{Discussion}

Gray mold is the most common fruit rotting pathogen of strawberry in Egypt and in the world. It is a major problem during bloom and on ripening, mature and harvested fruit, particularly during wet weather $[1,3]$. Botrytis fruit rot epidemics are typically started by spores produced on debris of strawberry in the field $[1,3]$. The fungus spreads very quickly by spores and infects different floral parts. Control of grey mould should be started at the beginning of flowering and the disease is usually controlled by chemical methods. Numerous studies have described the isolation of micro-organisms and demonstrated their potential to antagonize $[2,6]$. Bacteria-fungal pathogeninteractions are having an increased interest in the area of biocontrol $[1,9]$. Such methods involve either biological control or use of plant defense elicitors [10]. Many of the antifungal interactions involved Pseudomonas $s p$. In the present study, $P$. fluorescens bacterial strains was isolated from phyllosphere and tested for its antifungalability against pathogenic Botrytis. Bacteria showed that gray mold rot can be effectively controlled due to its antagonistic capability to inhibit the fungus, $B$. cinerea growth, on strawberry fruits. Also, we found that the bacteria produce antibiotic and siderophore which is vital

Table 2. Effect of glycerol oil formulation of Pseudomonas fluorescens on Botrytis blight of strawberry fruits under field conditions.

\begin{tabular}{ccccc}
\hline \multirow{2}{*}{ Treatments } & Application & Flower infection & \multicolumn{2}{c}{ Fruits infection } \\
\cline { 3 - 5 } & & & Disease severity (Scale 0 - 9) & Disease incidence \% \\
\hline \multirow{2}{*}{$\begin{array}{c}\text { Pseudomonas fluorescens } \\
\text { Fungicide }\end{array}$} & Once & $2.6 \mathrm{c}{ }^{* *}$ & $2.0 \mathrm{c}$ & $6.87 \mathrm{c}$ \\
Control & Twice & $0.8 \mathrm{~d}$ & $1.8 \mathrm{~d}$ & $2.65 \mathrm{~d}$ \\
\hline
\end{tabular}

*Figures with the same letter are not significantly different $(\mathrm{P}=0.05) ;{ }^{* *}$ Three replicates were used; ${ }^{* * *}$ Disease severity of Botrytis was measured using $1-9$ Scale, where $1=$ free from disease, and $9=$ killed.

Table 3. The growth response and yield of strawberry as affected by Pseudomonas fluorescens on the grey mould.

\begin{tabular}{|c|c|c|c|c|c|c|c|}
\hline \multirow{2}{*}{ Treatments } & \multirow{2}{*}{ Application } & \multicolumn{4}{|c|}{ Weight (g)/plant ${ }^{*}$} & \multicolumn{2}{|c|}{ Yield } \\
\hline & & Fresh & Increase \% & Dray & Increase \% & (tons/feddan) & Increase \% \\
\hline \multirow{2}{*}{$\begin{array}{l}\text { Pseudomonas } \\
\text { fluorescens }\end{array}$} & Once & $150 \mathrm{~b}^{* *}$ & $25.0 \mathrm{~b}$ & $27.0 \mathrm{~b}$ & $28.6 \mathrm{~b}$ & $7.5 \mathrm{c}$ & $25.0 \mathrm{c}$ \\
\hline & Twice & $170 \mathrm{a}$ & $41.7 \mathrm{a}$ & $29.0 \mathrm{a}$ & $38.1 \mathrm{a}$ & $8.6 \mathrm{a}$ & $43.0 \mathrm{a}$ \\
\hline Fungicide & & $140 \mathrm{c}$ & $16.6 \mathrm{c}$ & $24.0 \mathrm{c}$ & $14.3 \mathrm{c}$ & $8.1 \mathrm{bc}$ & $35.3 \mathrm{~b}$ \\
\hline Control & & $120 \mathrm{~d}$ & - & $21.0 \mathrm{~d}$ & - & $6.0 \mathrm{~d}$ & - \\
\hline
\end{tabular}

*Figures with the same letter are not significantly different $(\mathrm{P}=0.05) ;{ }^{* *}$ Three replicates were used. 
for biocontroling of this disease. The involvement of substances, siderophore or antibiotics, seems to play a role in the active principle of the present isolate as symptoms of inhibition of conidia of $B$. cinerea.

The genus Pseudomonas actively solubilizes phosphate in vitro and produces several antibiotics (DAPG and phenazine) and siderophore with high specificity against several microorganisms [11]. Pseudomonas spp. have been employed efficiently as biocontrol agents and present time there are some commercial products in the market, nevertheless, the applications of purified siderophores, as bacteriostatic or fungi static agents in combination with other antifungal factors will certainly raise a great interest [12]. Siderophores production by strains of Pseudomonas, as a constituent of biological products, for plant disease control, is of great interest because its possibilities in the substitution of chemical pesticides [8].

Batch and fed-batch processes have been established for improved production of biomass, siderophore and DAPG during cultivation of fluorescent pseudomonad. The process was established to produce these metabolites and biomass in a way to achieve desired levels of these metabolites based on the change in medium components and also the mode of operating the bioreactor. In general, the productivity of microbial metabolites is closely related to the fermentation process used [13]. The changes of nutrients and their concentrations have different effects on the accumulation of different metabolites, which are controlled by intracellular effectors. Where, the carbon and nitrogen source can dramatically influence antibiotic formation. Furthermore, storage of antagonist products is important our investigation showed a highly significant drop in cell viability within the first month of formulation. This could indicate that it might be commercially more feasible to prepare biofungicide on demand, unless a more stabilizing freezing medium or preservation method can be developed. In our investigation, a glycerol formulation ensured a high significant drop in viability $[12,14]$.

Twice foliar application of formulated bacterial on strawberry plants provided greater efficacy for controlling grey mould disease. This strain is promising for industrial application since they grow quickly in broth condition in simple and of a low cost process to enhance production yield, and the excreted siderophore are frequently required for industrial applications.

\section{Acknowledgements}

This research was supported financially by the Science and Technology Development Fund (STDF), Egypt, Grant No 216 under title: Development of Bioproducts as Bio-fungicides for Controlling of Major Foliar Diseases of Some Economic Horticultural Crops, from 2009-2012; PI. Wafaa M. Haggag.

\section{REFERENCES}

[1] W. M. Haggag, "Isolation of Bioactive Antibiotic Peptides from Bacillus brevis and Bacillus polymyxa against Botrytis Grey Mould in Strawberry," Archives Journal of Phytopathology and Plant Protection (German), Vol. 41, No. 7, 2008, pp. 477-491.

[2] H. Zhang, L. Wang, Y. Dong, S. Jiang, J. Cao and R. Meng, "Postharvest Biological Control of Gray Mold Decay of Strawberry with Rhodotorulaglutinis," Biological Control, Vol. 40, No. 2, 2007, pp. 287-292.

[3] B. Williamson, B. Tudzynski, P. Tudzynski and J. A. L. van Kan, "Botrytis cinerea: The Cause of Grey Mould Disease," Molecular Plant Pathology, Vol. 8, No. 5, 2007, pp. 561-580. doi:10.1111/j.1364-3703.2007.00417.x

[4] J. C. Sutton, "Evaluation of Micro-Organisms for Biocontrol: Botrytis cinerea and Strawberry, a Case Study," In: J. H. Andrews and I. C. Tommerup, Eds., Advances in Plant Pathology, Academic Press, San Diego, 1995.

[5] J. A. L. van Kan, "Licensed to Kill: The Lifestyle of a Necrotrophic Plant Pathogen," Trends in Plant Science, Vol. 11, No. 5, 2006, pp. 247-253.

[6] W. M. Haggag and H. A. A. Mohamed, "Biotechnological Aspects of Microorganisms Used in Plant Biological Control (Article)," American-Eurasian Journal of Sustainable Agriculture, Vol. 1, No. 1, 2007, pp. 7-12.

[7] J. M. Meyer and M. A. Abdallah, "The Florescent Pigment of Pseudomonas fluorescens Biosynthesis, Purification and Physicalchemical Properties," Journal of General Microbiology, Vol. 107, No. 2, 1978, pp. 319-328.

[8] E. María and D. M. E. de Villegas, "Biotechnological Production of Siderophores," In: A. Varma and S. Chincholkar, Eds., Microbial Siderophores, Vol. 12, Springer Verlag, Berlin, 2007, pp. 219-231.

[9] D. Rachid and B. Ahmed, "Effect of Iron and Growth Inhibitors on Siderophores Production by Pseudomonas fluorescens," African Journal of Biotechnology, Vol. 4, No. 7, 2005, pp. 697-702.

[10] N. Mohamed, J. Lherminier, M. J. Farmer, J. Fromentin, N. Beno, V. Houot, M. L. Milat and J. P. Blein, "Defense Responses in Grapevine Leaves against Botrytis cinerea Induced by Application of a Pythiumoligandrum Strain or Its Elicitin, Oligandrin, to Roots," Phytopathology, Vol. 97, No. 5, 2007, pp. 611-620. doi:10.1094/PHYTO-97-5-0611

[11] C. Voisard, C. Keel, D. Hass and G. Defago, "Cyanide Production by Pseudomonas fluorescens Suppress Helps Black Root Rot of Tobacco under Gnotobiotic Conditions," EMBO Journal, Vol. 8, No. 2, 1989, pp. 351-358.

[12] J. I. Cohen, C. Falconi and J. Komen, "Strategic Decisions for Agricultural Biotechnology," Synthesis of Four Policy Seminars, Vol. 38, 1998, pp. 1-11.

[13] C. Seuk, T. Paulita and R. Baker, "Attributes Associate with Increased Bio-Control Activity of Fluorescent Pseu- 

Metabolites for Biocontrol of Strawberry Grey Mould

domonads," Journal of Plant Pathology, Vol. 4, No. 3, 1988, pp. 218-225.

[14] G. Silva and E. de Almeida, "Production of YellowGreen Fluorescent Pigment by Pseudomonas fluores- cens," Brazilian Archives of Biology and Technology, Vol. 49, No. 3, 2006, pp. 411-419.

doi:10.1590/S1516-89132006000400009 